\title{
METHOD FOR EVALUATING THE THROUGHPUT PERFORMANCE OF SHUTTLE BASED STORAGE AND RETRIEVAL SYSTEMS
}

\author{
Tone Lerher, Banu Y. Ekren, Zaki Sari, Bojan Rosi
}

Original scientific paper

In this paper a method for throughput performance calculation of shuttle based storage and retrieval systems (SBS/RS) is presented. SBS/RS represent a new technology in automated storage and retrieval systems. Since it is important to design SBS/RS right the first time due to the relative inflexibility of the physical layout, we provide a proposed method for the throughput performance calculation of these systems. The performance of the system is considered as a throughput capacity of the SBS/RS as a whole.

Keywords: automated warehouses; performance analysis; shuttle based systems; throughput capacity

\section{Metoda za procjenu protočne performance automatiziranih skladišnih sustava s vozilima}

Izvorni znanstveni članka U ovom radu prezentira se metoda proračuna protočne performanse skladišnih sustava sa shuttle-ovima/vozilima (eng. SBS/RS). SBS/RS zastupaju novu tehnologiju automatiziranih skladišnih sustava. S obzirom na važnost ispravnog oblikovanja (projektiranja) SBS/RS sustava "od prve" zbog relativne nefleksibilnosti fizičke izvedbe, prezentira se predložena metoda proračuna protočne performanse takvih sustava. Performansa sustava razmatra se kao protočni kapacitet SBS/RS kao cjeline.

Ključne riječi: automatizirana skladišta; analiza performansi; protočni kapacitet; sustavi s vozilima (shuttle-ovima)

\section{Introduction}

Warehouses are critical for supply chains. To be able to increase space utilization in a warehouse, managers prefer a high-rise storage area with a relatively small footprint. Having numerous numbers of tiers in storage area creates necessity for fast and efficient storage and retrieval system to store/retrieve loads to/from storage locations to increase the throughput capacity. With advances in technology, new automated material handling technologies providing greater responsiveness and additional flexibility in fulfilling orders have been developed [1]. A major segment in the material handling industry is the Automated Storage and Retrieval System (AS/RS). There are primarily two types of AS/RS traditional, Crane-Based Automated Storage and Retrieval System (CBAS/RS) and the Autonomous Vehicle-Based Storage and Retrieval Systems (AVS/RS).

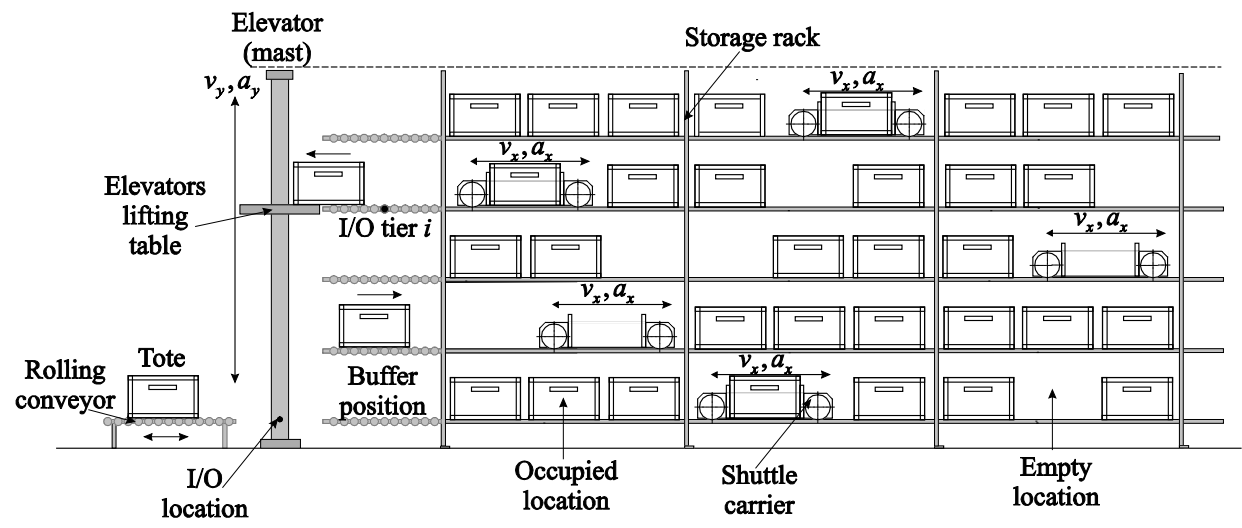

Figure 1 Shuttle based storage and retrieval system [23]

CBAS/RS are widely used in warehouses throughout the world. CBAS/RS usually consist of conveyors, storage racks and automated Storage/Retrieval (S/R) machine (crane) [2]. The $S / R$ machine is fully automated and can travel in narrow aisles between the storage racks to store and retrieve loads. The $\mathrm{S} / \mathrm{R}$ machine can manipulate either pallets (unit load AS/RS) or totes/cartons (mini-load AS/RS). The major difference between the unit-load and the mini-load system is in the $\mathrm{S} / \mathrm{R}$ machine design. The latter has the consequence on the kinematic properties of the crane and the hoisted carriage, which can reach higher velocities and throughput in the case of the mini-load systems.

Advances in Autonomous Vehicle (AV) hardware technologies have helped manufacturers of material handling systems to pursue the use of AV instead of fixed- cranes in Unit-Load (UL) warehouses. AVS/RS, a relatively new technology for automated UL warehouses, has been implemented at scores of facilities, primarily in Europe [3]. Due to the ability of accessing any storage positions in the storage racks and flexibility in changing the number of $\mathrm{AV}$, this system has advantages compared to traditional CBAS/RS. 
Shuttle Based Storage and Retrieval System (SBS/RS) is a new technology in AVS/RS and usually works with aisle and tier captive shuttles. This new technology is mostly used for mini-load warehouses [4, 5]. The vertical movement of totes is facilitated by elevators lifting table mounted along the periphery of the storage racks. Shuttle carriers follow horizontal movement.

It is important to design SBS/RS right the first time due to the relative inflexibility of the physical layout and the equipment. To be able to evaluate the performance of these designs, fast working method is required. In this paper, the proposed method for the throughput performance calculations of SBS/RS is presented.

\section{$2 \quad$ Literature review}

AVS/RS is first studied by Malmborg [3]. Malmborg [6] proposes an analytical model for estimating the proportion of Dual Command (DC) cycles in AVS/RS. The proposed model provides a useful tool in predicting the DC cycles, although it has some limitations.

Kuo et al. [7] proposed another analytical model for AVS/RS predicting the resource utilization performance measure. The proposed model is performed on twelve different scenarios to test its efficiency. It is observed that the proposed analytical model provides good estimates of vehicle utilization and system cost for the studied AVS/RS. Later, Kuo et al. [8] proposed a model based on a queuing network approach to estimate the performance measures from AVS/RS. The model is capable of efficiently generating estimates of resource utilizations in AVS/RS based on alternative class-based storage schemes.

Fukunari and Malmborg [9] developed an efficient cycle time model for AVS/RS based on queuing modelling and compare their performance with traditional $\mathrm{CBAS} / \mathrm{RS}$. The model is based on an iterative computational scheme considering random storage assignment policy. This model also improves upon earlier models by scaling efficiently for large problems. The performance of the procedure is shown on realistically sized problems. Later, Fukunari and Malmborg [10] proposed another queuing network approach estimating the resource utilizations in AVS/RS. This model also provides reasonably accurate estimates for the resource utilization of the studied system.

Zhang et al. [11] studied a queuing modelling approach to estimate the waiting times of transactions in AVS/RS. The proposed model is variance based that dynamically selects among three alternative queuing approximations based on the Squared Coefficient of Variation (SCV) of transaction inter-arrival times. The proposed model's results show greater accuracy in estimation of transaction waiting times and thereby enabling more effective design conceptualization. They also present the proposed models via online tools to let the warehouse designers and analysts develop alternate AS/RS and AVS/RS warehouse configurations.

Recently, Ekren et al. [12], Ekren [13] and Ekren and Heragu [14] have studied simulation based performance evaluation of AVS/RS. They study near optimum storage rack configuration design under pre-defined scenarios of number of vehicles and lifts in the system. They use simulation based regression analysis [15] and implement a design of experiments for an AVS/RS to identify factors affecting its performance [15].

Roy et al. [16] studied a Semi-Open Queuing Network (SOQN) model to evaluate the design trade-offs in a single tier of an AVS/RS. Their model captures the effect of location of the vehicles within a tier using multiple vehicle classes and class switching probabilities. They solved the developed SOQN model by a decomposition approach. The results suggest that having multiple zones is better due to reduction in travel time along the cross-aisle.

Ekren et al. [17, 18] also study SOQN to model an AVS/RS. They use their pre-proposed extended algorithm [19] to calculate the performance measures, particularly utilization of resources and waiting times in resource queues, from the system. By this study, they showed that the system could be modelled by SOQN and solved efficiently by their extended algorithm.

The most related paper to the studied system is completed by Carlo and Vis [4]. They study a type of SBS/RS where there are two non-passing lifting systems mounted along the storage rack. They complete their study for a company providing solutions on these systems. They focus on scheduling problem where two (piece-wise linear) functions are introduced to evaluate candidate solutions.

Later, Marchet et al. [20] simulated an SBS/RS to observe the main trade-offs. They considered several warehouse design scenarios in terms of storage rack design. They provide several performance measures from the system also including cost.

Lerher et al. [21] study multi-objective optimization for automated warehouses. For the solution procedure, they utilized genetic algorithm. Recently, Lerher [22] and Lerher et al. [5] have studied energy efficient warehouse design in automated warehousing, e.g. in SBS/RS. The proposed models enable reduction of energy consumption and consequently the $\mathrm{CO}_{2}$ emissions produced in SBS/RS warehouses. Several design scenarios are considered in terms of storage rack design and material handling equipment velocities to test how the energy consumption is affected by these designs. By these studies, it is believed that the energy and environment aspect indubitably brought changes into planning of warehouses and caused a great challenge for those who are engaged in the automated warehousing planning process. Lerher at al. [23] proposed analytical travel time model for the computation of travel (cycle) time for SBS/RS. The proposed model considers the operating characteristics of the elevators lifting table and the shuttle carrier, such as acceleration and deceleration and the maximum velocity. The proposed model enables the calculation of the mean travel (cycle) time for the single and dual command cycles, from which the performance of SBS/RS can be evaluated.

Smewet al. [24] presented a simulation study to define trade-off between the conflicting objectives of maximising customer service level and minimising WorkIn-Process. Bekker [25] proposed a computationally economic approach to optimise throughout rate and 
allocated buffer space, which are the two conflicting objectives of the buffer allocation problem.

Regarding the warehouse informatization, Erkan and Can [26] proposed Analytic Hierarchy Process (AHP) and Fuzzy Analytic Hierarchy Process (FAHP) for selecting between barcode and Radio Frequency Identification (RFID) systems for the company warehouse data collection system.

Different from the existing studies, we propose the throughput performance calculations method of SBS/RS by implementing several warehouse designs. We show our results for the selected velocity profile of the elevators lifting table and for the shuttle carrier and several scenarios for storage rack configurations.

\section{Method for the throughput performance calculations}

SBS/RS are composed of elevators with lifting tables that are attached on a mast, shuttle carriers, buffer positions and the storage racks (Fig. 1).

The elevators lifting table provides vertical movement for totes to reach the prescribed tier in the $\mathrm{SBS} / \mathrm{RS}$. The elevators lifting table can reach up to $v_{y}=$ $1,5 \mathrm{~m} / \mathrm{s}$ and more. Elevators are usually bottlenecks in the system so that they determine the performance of the whole system $[22,23]$.

A shuttle carrier is a tier-captive autonomous vehicle with four wheels that transports totes from buffer position to storage locations in the storage racks. It is equipped with telescopic attachment for manipulating totes. The maximal weight of a tote should not exceed $50 \mathrm{~kg} /$ shuttle carrier and its dimensions should be in the range of: min. $(150 \times 200 \times 80) \mathrm{mm}$, max. $(600 \times 400 \times 250) \mathrm{mm}$. A shuttle carrier can travel up to $v_{x}=4 \mathrm{~m} / \mathrm{s}[22,23]$.

In SBS/RSs, there is usually a single shuttle carrier in each tier of storage rack (tier-captive system). This assumption can be released if we use a special shuttle elevator at the back of the storage rack, for moving shuttle carriers up and down to the prescribed tier in the storage rack (tier-to-tier system) [22, 23].There are two buffer positions, each serving one side in storage rack at each tier. These positions are used for buffering totes carried by lifts for storage process and by shuttles for retrieval process. The storage rack is composed of storage columns $C$. By multiplying storage columns $C$ in the horizontal and tiers $T$ in the vertical direction, the total number of storage locations $Q$ is achieved.

When building the simulation model of SBS/RS, the following assumptions and notations were considered [23].

- The SBS/RS is divided into two sides in an aisle. So, totes can be stored at either side in a tier.

- The input/output (I/O) location of the SBS/RS is located at the first tier, next to the lift location (Fig. 1).

- The storage rack is divided by columns and tiers. At each tier, there are two buffer positions (left and right) and a single shuttle carrier (aisle-captive system).

- The elevator manipulates two lifting tables independently one of which is located at the left side and the other one is located at the right side of the elevator. Each lifting table can serve one tote at a time (Fig. 1).
- The elevator and shuttle carrier complete single and dual command cycles.

- Drive characteristics $\left(v_{y}, a_{y}\right)$ of the elevators lifting table as well as the height $H_{\mathrm{SR}}$ of the storage rack are known in advance.

- Drive characteristics of the shuttle carrier $\left(v_{x}, a_{x}\right)$ as well as the length $L_{\mathrm{SR}}$ of the storage racks are known in advance.

- The height $H_{\mathrm{SR}}$ and length $L_{\mathrm{SR}}$ of the storage racks are large enough for the elevators lifting table and the shuttle carrier to reach their maximum velocity $v_{\max }$ in the vertical and in the horizontal direction.

- Randomized assignment policy is considered which means that any storage position is equally likely to be selected for storage or retrieval location to be processed.

We summarize the acronyms and notations in the paper as listed below:

Abbreviations:

AS/RS Automated storage and retrieval systems.

AVS/RS Autonomous vehicle storage and retrieval systems.

AV Autonomous vehicle.

$\mathrm{CO}_{2} \quad$ Carbon dioxide.

SCV Coefficient of variation.

CBAS/RS Crane based automated storage and retrieval systems.

DC Dual command.

I/O Input and output.

SOQN Semi-open queuing network.

SBS/RS Shuttle based storage and retrieval systems.

SC Single command.

$\mathrm{S} / \mathrm{R} \quad$ Storage and retrieval.

UL Unit load.

Symbols: $a$

$a_{x} \quad$ Acceleration/deceleration of the shuttle carrier in the horizontal direction.

$a_{y} \quad$ Acceleration/deceleration of the elevators lifting table in the vertical direction.

$d(T) \quad$ Distance in dependence of time.

$\eta \quad$ Efficiency.

$\tau \quad$ Expected bottleneck.

$h_{\text {tote }} \quad$ Height of the tote (plastic container).

$h_{\mathrm{COM}} \quad$ Height of the storage cell (tier).

$H_{\mathrm{SR}} \quad$ Height of the storage rack.

$l_{\text {tote }} \quad$ Length of the tote (plastic container).

$l_{\mathrm{COM}} \quad$ Length (depth) of the storage cell.

$L_{\mathrm{SR}} \quad$ Length of the storage rack.

$T \quad$ Number of tiers.

$C \quad$ Number of columns.

$A \quad$ Number of aisles.

$v_{\max } \quad$ Maximum velocity.

$T(\mathrm{SC})_{\text {lift }}$ Single command cycle time of the elevators lifting table.

$T$ (DC) $)_{\text {lift }}$ Dual command cycle time of the elevators lifting table.

$\overline{T(\mathrm{DC})}_{\text {lift }}$ Mean dual command cycle time of the elevators lifting table. 


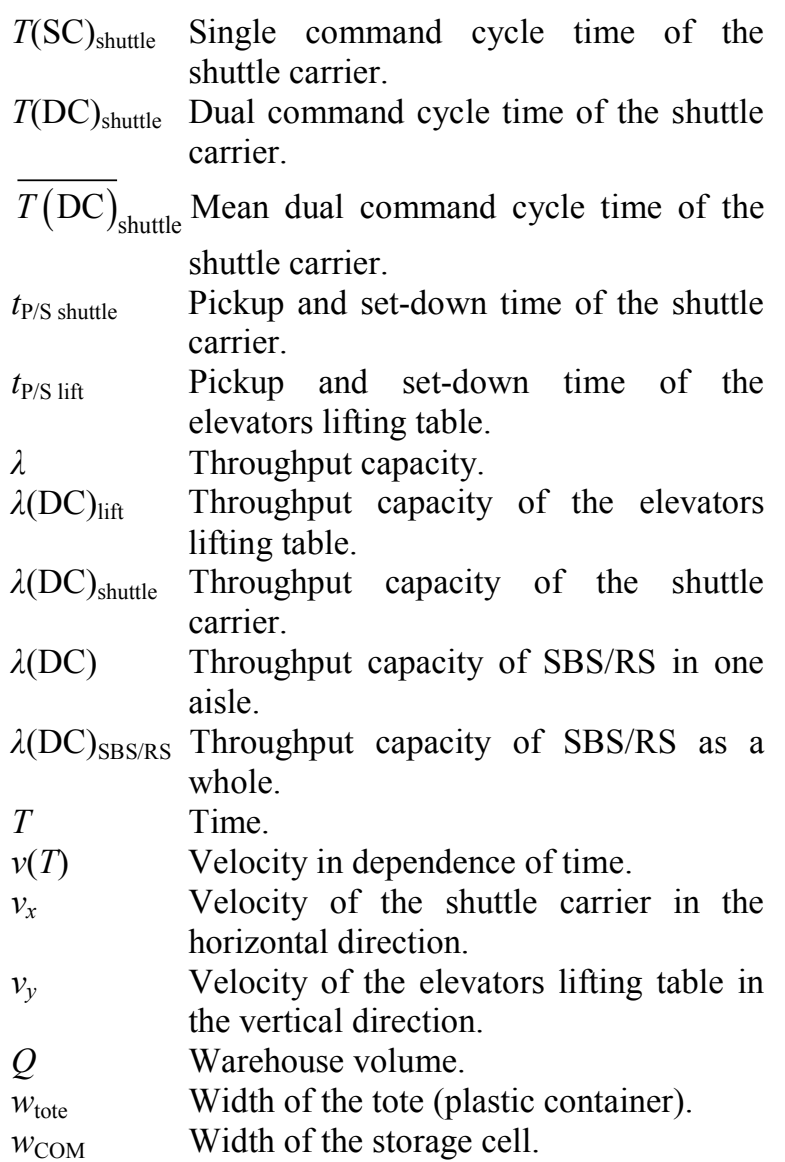

\subsection{Simulation model of SBS/RS}

To facilitate the performance evaluation of the SBS/RS, the discrete event simulation was employed [23].The simulation model begins with the process which marks all storage locations in the SBS/RS according to the prescribed storage area. After creating the list of free storage locations, enter in the simulation model the first tote, which is situated in the input/output $(\mathrm{I} / \mathrm{O})$ location of the SBS/RS. Further on, the tote receives a sign, which belongs to the buffer position in the $i^{\text {th }}$ tier and the storage location in the $i^{\text {th }}$ tier. The elevators lifting table picks up the tote from the $\mathrm{I} / \mathrm{O}$ location and moves to the buffer position in the $i^{\text {th }}$ tier.

After conducting transport to the buffer location in the $i^{\text {th }}$ tier, the elevators lifting table set down the tote, which is waiting to be moved by a shuttle carrier. Next the shuttle carrier picks up the tote from the buffer position in the $i^{\text {th }}$ tier and travels to the $j^{\text {th }}$ storage location, where the tote is set down by a shuttle carrier. For the storage operation, the randomized storage policy has been used. Next, the tote that has been stored the $i^{\text {th }}$ storage location is put on the waiting list by a computer (computer data base), where it waits for the retrieval operation. For the retrieval process the random request selection rule has been used.

After the storage operation in the $i^{\text {th }}$ tier, the shuttle carrier travels to the $j^{\text {th }}$ retrieval location. The retrieval location is positioned in the same tier (application of the tier-captive system). Next, the shuttle carrier picks up the tote and moves to the buffer position in the $i^{\text {th }}$ tier, where the tote is picked up by the elevators lifting table.
The average cycle time for the transaction is therefore associated with moving of the elevators lifting table and travelling of the shuttle carrier.

Movement of the elevators lifting table and travelling of the shuttle carrier in the simulation model is based on the velocity-time dependence. Two types of velocity profiles can be distinguished depending on whether the obtained peak velocity $v\left(t_{p}\right)$ is less than $v_{\max }$ (type I) or equal to $v_{\max }$ (type II) (Fig. 2). It can be verified that time $T<2 v_{\max } / a$ for type I and $T>2 v_{\max } / a$ for type II [23].
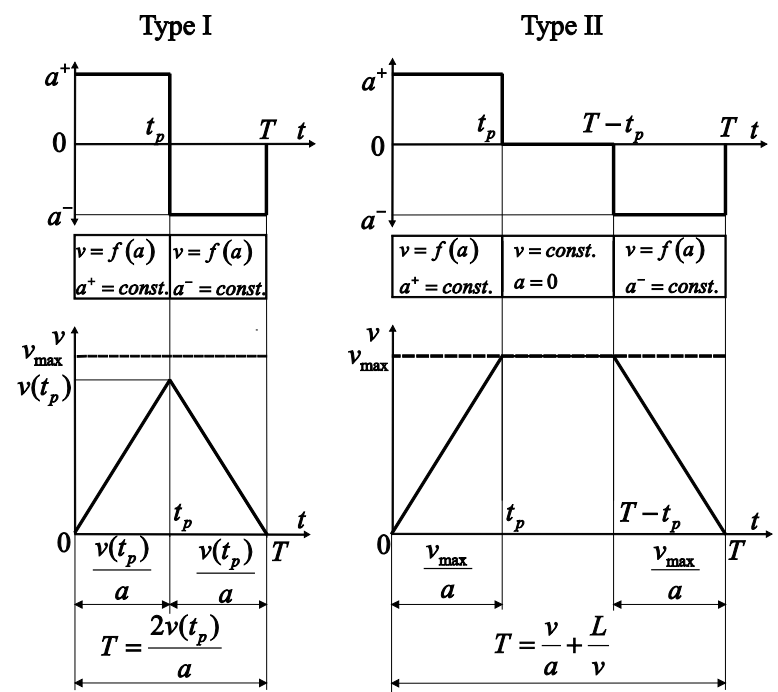

Figure 2 Velocity time dependence for type I and II [23]

\section{Velocity-time dependence for type I}

The velocity in dependence of time $v(t)$ equals the following expression:

$v(t)=\left\{\begin{array}{lc}a t, & t \in\left(0, t_{p}\right) \\ -a(t-T), & t \in\left(t_{p}, T\right)\end{array}\right.$,

The distance in dependence of time $d(T)$ equals the following expression:

$d(T)=\int_{0}^{T} v(t) d t=\frac{a \cdot T^{2}}{4}$,

Because of the acceleration and deceleration are equal in magnitude, the time necessary to reach the peak velocity equals $t_{p}=T / 2$. For the verification of the expression 2 see Appendix A.

\section{Velocity-time dependence for type II}

The velocity in dependence of time $v(t)$ equals the following expression:

$$
v(t)= \begin{cases}a t, & t \in\left(0, t_{p}\right) \\ v_{\max }, & t \in\left(t_{p}, T-t_{p}\right), \\ -a(t-T), & t \in\left(T-t_{p}, T\right)\end{cases}
$$


The distance in dependence of time $d(T)$ equals the following expression:

$$
d(T)=\int_{0}^{T} v(t) d t=v_{\max } \cdot T-\frac{v_{\max }^{2}}{a},
$$

For the verification of the expression 4 see Appendix A.

As a performance measure for the SBS/RS, the mean cycle time and consequently the throughput capacity have been used. The throughput capacity represents the number of transactions (stores and retrievals) that the system can perform in a given time period. The throughput capacity is inversely dependent on the average cycle time.

\subsection{Throughput performance of the elevator}

The elevator carries two lifting tables at both sides (left and right). Both lifting tables work independently of each other and thus double throughput capacity can be achieved.

The elevators lifting table can work on a Single Command (SC) cycle, which means that only one tote can be handled in a cycle.

More advanced is Dual Command (DC) cycle, by which two totes are handled in a cycle (Fig. 3). For the calculation of the SC and DC cycles of the elevators lifting table, the simulation model of the SBS/RS has been employed.

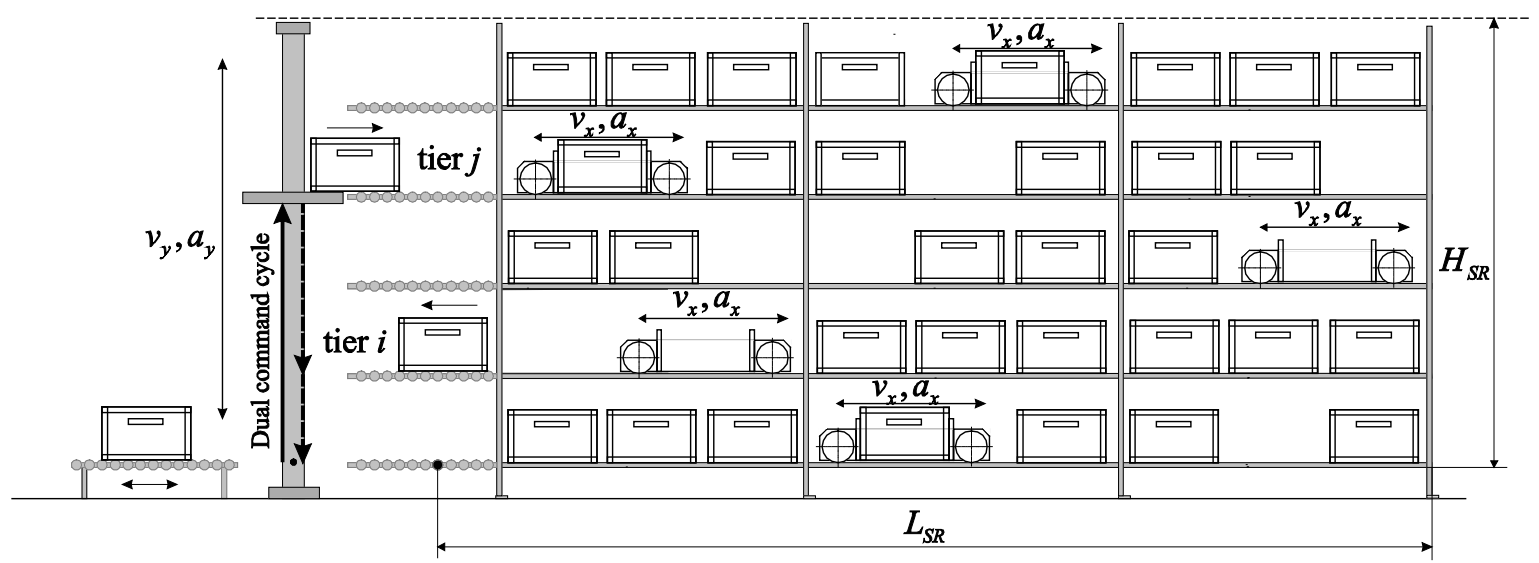

Figure 3 Dual command cycle of the elevators lifting table [23]

\subsubsection{Single command cycle}

In the case of SC cycle, the elevators lifting table moves a tote from the $\mathrm{I} / \mathrm{O}$ location to randomly selected tier $j$, unloads the tote and moves back to the I/O location. The same sequence can also be performed in the reverse order.

Single command cycle time $T(\mathrm{SC})_{\text {lift }}$ can be calculated by simulation using expression (5):

$T(\mathrm{SC})_{\text {lift }}=2 \cdot t_{\mathrm{P} / \mathrm{S} \mathrm{lift}}+2 \cdot t_{\mathrm{I} / \mathrm{O}, j}$

\subsubsection{Dual command cycle}

In the case of DC cycle, the elevators lifting table moves a tote from the I/O location to randomly selected tier $j$, unloads the tote and moves further to randomly selected tier $i$, where the tote is retrieved. After loading the tote at tier $i$, the elevators lifting table moves back to the I/O location (Fig. 3).

Dual command cycle time $T(\mathrm{DC})_{\text {lift }}$ can be calculated by simulation using expression (6):

$$
T(\mathrm{DC})_{\mathrm{lift}}=4 \cdot t_{\mathrm{P} / \mathrm{S} \text { lift }}+t_{\mathrm{I} / \mathrm{O}, j}+t_{j, i}+t_{i, \mathrm{I} / \mathrm{O}},
$$

\subsubsection{Throughput performance calculation}

By considering (6) the throughput performance of the elevators lifting tables in case of DC cycles per hour is calculated by (7):

$$
\lambda(\mathrm{DC})_{\text {lift }}=\frac{3600}{T(\mathrm{DC})_{\text {lift }}} \cdot k \cdot n,
$$

where $k=2$, due to the DC and $n=2$ due to the elevator with two lifting tables.

\subsection{Throughput performance of the shuttle carrier}

A shuttle carrier can receive one tote at a time and can operate on a SC cycle or DC cycle. For the calculation of the SC and DC cycles of the shuttle carrier, the simulation model of the SBS/RS has been employed.

\subsubsection{Single command cycle}

The operation of SC cycle encompasses either storage or a retrieval assignment. After completing a given storage or retrieval assignment at point $P_{i}$, the shuttle carrier returns directly to the $\mathrm{I} / \mathrm{O}_{\text {tier } j}$. In the case of $\mathrm{SC}$ cycle, the shuttle carrier operates only one tote in the cycle.

Single command cycle time $T(\mathrm{SC})_{\text {shuttle }}$ can be calculated by simulation using expression (8):

$$
T(\mathrm{SC})_{\text {shuttle }}=2 \cdot t_{\mathrm{P} / \mathrm{S} \text { shuttle }}+2 \cdot t_{\mathrm{I} / \mathrm{O}_{\text {tier }},}, P_{i},
$$




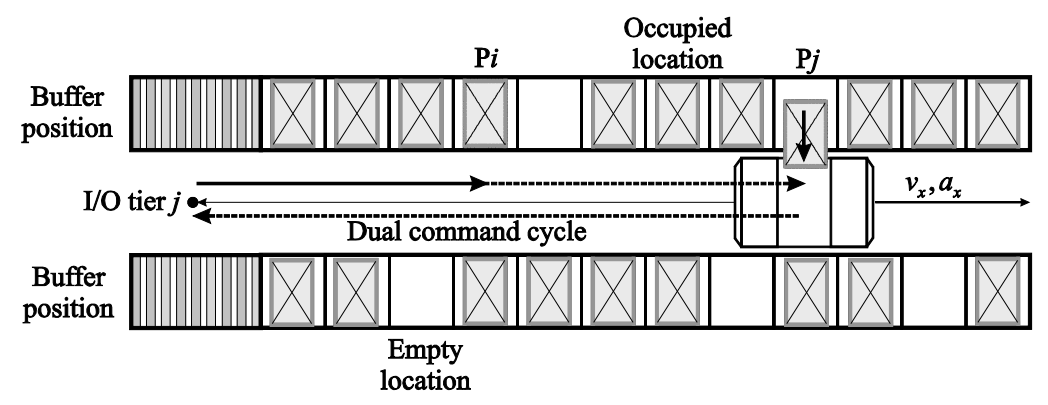

Figure 4 Dual command cycle of the shuttle carrier [23]

\subsubsection{Dual command cycle}

The operation of DC cycle considers storage and retrieval assignment in a cycle (Fig. 4). Recall that in DC cycle, the shuttle carrier travels to two storage locations between successive returns to the $\mathrm{I} / \mathrm{O}_{\text {tieri. }}$. After completing a given storage request at point $P_{i}$, the shuttle carrier moves directly to another storage location for the next retrieval request at point $P_{j}$ without returning to the $\mathrm{I} / \mathrm{O}_{\text {tierj. }}$

Dual command cycle time $T(\mathrm{DC})_{\text {shutle }}$ can be calculated by simulation using expression (9):

$$
T(\mathrm{DC})_{\text {shuttle }}=4 \cdot t_{\mathrm{P} / \mathrm{S} \text { shuttle }}+t_{\mathrm{I} / \mathrm{O}_{\text {tier }}, P_{i}}+t_{P_{i}, P_{j}}+t_{P_{j}, \mathrm{I} / \mathrm{O}_{\text {tier }}},
$$

\subsubsection{Throughput performance calculation}

By considering (9) the throughput performance of all shuttle carriers in case of DC cycles per hour is calculated by (10):

$$
\lambda(\mathrm{DC})_{\text {shuttle }}=\frac{3600}{T(\mathrm{DC})_{\text {shuttle }}} \cdot k \cdot m
$$

where $k$ is 2 , due to the DC cycle and $m=T$ due to the application of the tier-captive SBS/RS.

\section{SBS/RS under study}

In this section, main input data for the analysis are provided and discussed.

Stock keeping unit represents a tote (plastic container) filled with items with the dimensions: length $l_{\text {tote }}=0,6 \mathrm{~m}$, width $w_{\text {tote }}=0,4 \mathrm{~m}$ and height $h_{\text {tote }}=0,24 \mathrm{~m}$.

With regard to the tote, the storage compartment (cell) has the following dimensions: length (depth) of the storage cell $l_{\mathrm{COM}}=0,6 \mathrm{~m}$, width of the storage cell $w_{\mathrm{COM}}=$ $0,5 \mathrm{~m}$ and height of the cell (tier) $h_{\mathrm{COM}}=0,35 \mathrm{~m}$.

Dimensions of the SBS/RS storage rack ( $L_{\mathrm{SR}}$ and $\left.H_{\mathrm{SR}}\right)$ depend on the number of columns $C$ in the horizontal direction and number of tiers $T$ in the vertical direction, respectively.

As it will be seen in Tab. 1, nine (9) different SBS/RS configurations were analysed based on three values of tiers $T(T=10,15$ and 20) and three values of aisles $A(A$ $=3,6$ and 9) [20].

Total number of storage locations - $Q$ - is assumed to be approximately 10000 storage locations [20].

\begin{tabular}{|c|c|c|c|c|}
\multicolumn{7}{l}{ Table 1 SBS/RS configurations $[20]$} \\
\hline $\mathrm{RC} i$ & $T / A$ & $C$ & $L_{\mathrm{SR}} / H_{\mathrm{SR}}$ & $Q$ \\
\hline 1 & $10 / 3$ & 167 & $83,5 / 3,5$ & 10020 \\
\hline 2 & $10 / 6$ & 84 & $42 / 3,5$ & 10080 \\
\hline 3 & $10 / 9$ & 56 & $28 / 3,5$ & 10080 \\
\hline 4 & $15 / 3$ & 112 & $56 / 5,25$ & 10080 \\
\hline 5 & $15 / 6$ & 56 & $28 / 5,25$ & 10080 \\
\hline 6 & $15 / 9$ & 38 & $19 / 5,25$ & 10260 \\
\hline 7 & $20 / 3$ & 84 & $42 / 7,0$ & 10080 \\
\hline 8 & $20 / 6$ & 42 & $21 / 7,0$ & 10080 \\
\hline 9 & $20 / 9$ & 28 & $14 / 7,0$ & 10080 \\
\hline
\end{tabular}

Since the throughput capacity $\lambda$ greatly depends on the velocity characteristics of the elevators lifting table and the shuttle carrier, selected velocity scenario has been used in our analysis (Tab. 2).

Table 2 Velocity scenario of the shuttle carrier and the elevators lifting

\begin{tabular}{|c|c|}
\multicolumn{2}{|c}{ table } \\
\hline Shuttle carrier travelling & Lifting table movement
\end{tabular} \begin{tabular}{c|c}
$\begin{array}{c}\text { Shuttle carrier travelling } \\
\text { in the horizontal direction }\end{array}$ & $\begin{array}{l}\text { Lifting table movement } \\
\text { in the vertical direction }\end{array}$ \\
\hline
\end{tabular}

\begin{tabular}{|c|c|c|c|}
\hline$v_{x}(\mathrm{~m} / \mathrm{s})$ & $a_{x}\left(\mathrm{~m} / \mathrm{s}^{2}\right)$ & $v_{y}(\mathrm{~m} / \mathrm{s})$ & $a_{y}\left(\mathrm{~m} / \mathrm{s}^{2}\right)$ \\
\hline 1,5 & 1,5 & 1,5 & 1,5 \\
\hline
\end{tabular}

Note: Velocity scenario is selected according to the references of material handling equipment producers and practical experiences of the authors.

Other data that were used in the analyses are presented in Tab. 3.

Table 3 Other data used in analysis

\begin{tabular}{|c|c|c|}
\hline $\begin{array}{c}\text { Pick up / Deposit } \\
\text { time }\end{array}$ & Unit of measure & Data \\
\hline$t_{\mathrm{P} / \mathrm{S} \text { shuttle }}$ & sec. & 3,0 \\
\hline$t_{\mathrm{P} / \mathrm{S} \text { lift }}$ & sec. & 1,5 \\
\hline
\end{tabular}

Note: SBS/RS configurations are selected according to the references of material handling equipment producers and practical experiences of the authors.

\section{Throughput performance of the SBS/RS}

Tab. 4 summarizes mean DC cycle time of the elevators lifting table $\overline{T(\mathrm{DC})}_{\text {lift }}$ and the shuttle carrier $\overline{T(\mathrm{DC})}_{\text {shuttle }}$.

Tab. 5 summarizes throughput performance of the elevators lifting tables $\lambda(\mathrm{DC})_{\text {lift }}$ and the shuttle carriers $\lambda(\mathrm{DC})_{\text {shuttle. }}$

Tab. 6 summarizes the throughput performance of the SBS/RS as a whole. The throughput performance $\lambda(\mathrm{DC})_{\mathrm{SBS} / \mathrm{RS}}$ is calculated according to the expressions (11), (12), (13) and (14).

Because the SBS/RS are composed of the elevators lifting tables and the tier-captive shuttle carriers that are 
working independently from each other, the possible bottleneck is required to be found for calculating the SBS/RS throughput performance.

$\mathrm{RC} i$ column shows nine rack configurations for the SBS/RS defined in Tab. 1. Recall that means DC cycle times of the elevators lifting table $\overline{T(\mathrm{DC})_{\text {lift }}}$ and the shuttle carrier $\overline{T(\mathrm{DC})_{\text {shuttle }}}$ are calculated according to the large number of successive simulations.

Table 4 Travel time analysis

\begin{tabular}{|c|c|c|}
\hline RCi $i$ & $\overline{T(\mathrm{DC})_{\text {shuttle }}(\mathrm{s})}$ & $\overline{T(\mathrm{DC})_{\text {lift }}}$ (s) \\
\hline 1 & 89,5 & \multirow{2}{*}{11,70} \\
\hline 2 & 52,4 & \multirow{2}{*}{13,30} \\
\hline 3 & 39,9 & \\
\hline 4 & 64,9 & \multirow{2}{*}{15,00} \\
\hline 5 & 39,9 & \\
\hline 6 & 32,0 & \\
\hline 7 & 52,4 & \\
\hline 8 & 33,9 & \\
\hline 9 & 27,5 &
\end{tabular}

Table 5 Throughput capacity analysis

\begin{tabular}{|c|c|c|}
\hline $\mathrm{RC} i$ & $\begin{array}{c}\lambda(\mathrm{DC})_{\text {shuttle }} \\
(\text { totes } / \mathrm{h})\end{array}$ & $\begin{array}{l}\lambda(\mathrm{DC})_{\text {lift }} \\
\text { (totes } / \mathrm{h})\end{array}$ \\
\hline 1 & 804 & \multirow{3}{*}{1231} \\
\hline 2 & 1374 & \\
\hline 3 & 1805 & \\
\hline 4 & 1664 & \multirow{3}{*}{1083} \\
\hline 5 & 2707 & \\
\hline 6 & 3375 & \\
\hline 7 & 2748 & \multirow{3}{*}{960} \\
\hline 8 & 4248 & \\
\hline 9 & 5236 & \\
\hline
\end{tabular}

The throughput performance of the elevators lifting tables $\lambda(\mathrm{DC})_{\text {lift }}$ and the shuttle carriers $\lambda(\mathrm{DC})_{\text {shuttle, }}$ are calculated by using (7) and (10), respectively.

The efficiency $\eta$ of the elevators lifting table and the shuttle carrier is calculated by (11):

$\eta=\frac{\min \left(\lambda(\mathrm{DC})_{\text {shuttle }}, \lambda(\mathrm{DC})_{\text {lift }}\right)}{\max \left(\lambda(\mathrm{DC})_{\text {shuttle }}, \lambda(\mathrm{DC})_{\text {lift }}\right)}$

The expected bottleneck is found by the letter $\tau$ and is calculated by (12):

$$
\tau=\max \left(\lambda(\mathrm{DC})_{\text {shuttle }}, \lambda(\mathrm{DC})_{\mathrm{lift}}\right),
$$

The throughput capacity of SBS/RS in one aisle is calculated by (13):

$$
\lambda(\mathrm{DC})=\min \left(\lambda(\mathrm{DC})_{\text {shuttle }}, \lambda(\mathrm{DC})_{\text {lift }}\right),
$$

The whole $\mathrm{SBS} / \mathrm{RS}$ system performance $\lambda(\mathrm{DC})_{\mathrm{SBS} / \mathrm{RS}}$ is calculated by (14):

$\lambda(\mathrm{DC})_{\mathrm{SBS} / \mathrm{RS}}=A \cdot \lambda(\mathrm{DC})$

According to the results presented in Tab. 6, the throughput performance of the SBS/RS is influenced by the number of tiers $T$, number of aisles $A$, number of columns $C$, the velocity of the elevators lifting table $\left(v_{y}\right.$, $\left.a_{y}\right)$ and the velocity of the shuttle carriers $\left(v_{x}, a_{x}\right)$.

\begin{tabular}{|c|c|c|c|c|c|c|c|c|}
\hline $\mathrm{RC} i$ & $\begin{array}{c}\lambda(\mathrm{DC})_{\text {shuttle }} \\
(\text { totes } / \mathrm{h})\end{array}$ & $\begin{array}{l}\lambda(\mathrm{DC})_{\text {lift }} \\
(\text { totes } / \mathrm{h})\end{array}$ & $\eta_{\text {lift }}$ & $\eta_{\text {shuttle }}$ & $\tau$ & $\begin{array}{c}\lambda(\mathrm{DC}) \\
(\text { totes } / \mathrm{h})\end{array}$ & $A$ & $\begin{array}{c}\lambda(\mathrm{DC})_{\mathrm{SBS} / \mathrm{RS}} \\
(\text { totes } / \mathrm{h})\end{array}$ \\
\hline 1 & 804 & 1231 & 0,65 & 1,00 & shuttle & 804 & 3 & 2413 \\
\hline 2 & 1374 & 1231 & 1,00 & 0,90 & lift & 1231 & 6 & 7385 \\
\hline 3 & 1805 & 1231 & 1,00 & 0,68 & lift & 1231 & 9 & 11077 \\
\hline 4 & 1664 & 1083 & 1,00 & 0,65 & lift & 1083 & 3 & 3248 \\
\hline 5 & 2707 & 1083 & 1,00 & 0,40 & lift & 1083 & 6 & 6496 \\
\hline 6 & 3375 & 1083 & 1,00 & 0,32 & lift & 1083 & 9 & 9744 \\
\hline 7 & 2748 & 960 & 1,00 & 0,35 & lift & 960 & 3 & 2880 \\
\hline 8 & 4248 & 960 & 1,00 & 0,23 & lift & 960 & 6 & 5760 \\
\hline 9 & 5236 & 960 & 1,00 & 0,18 & lift & 960 & 9 & 8640 \\
\hline
\end{tabular}

Table 6 Throughput performance of the SBS/RS

NOTE: $\lambda(\mathrm{DC})_{\mathrm{SBS} / \mathrm{RS}}=\lambda(\mathrm{DC}) \cdot A$

The system performance mainly depends on the performance of the elevators lifting tables feeding the storage racks. Since a shuttle carrier can handle more work than an elevator, the assumption of tier-captive shuttles can be released.

In more advanced systems, a shuttle carrier can by using a special elevator at the back of the storage rack, operate in more tiers than in a single one.

Since the throughput performance of a SBS/RS is determined by the elevator, the elevator should receive the most of the attention when designing SBS/RS.

\section{Conclusion}

In this paper, a method for calculating the system performance of a SBS/RS is presented. The proposed method consists of calculations for the throughput capacity of the elevators lifting tables and the shuttle carriers of the SBS/RS.

SBS/RS are usually used by the companies dealing with large number of small sized orders requiring to be processed in a relatively short time period. In practice, there is an approximation that this system could reach up to 1000 totes per hour.

The proposed method presents an efficient approach for evaluating the system (throughput) performance of the SBS/RS. The system performance is manly influenced by the following decision variables: $(i)$ number of tiers $T$, (ii) 
number of aisles $A$, (iii) number of columns $C$, (iv) velocity of the elevators lifting table $\left(v_{y}, a_{y}\right)$ and $(v)$ velocity of the shuttle carriers $\left(v_{x}, a_{x}\right)$. Since the elevator (elevators lifting tables) works most of the time with the efficiency $\eta=1,0$ the system performance will greatly depend on the number of columns $C$ and number of aisles $A$. In case of small number of columns $C$ and large number of aisles $A\left(\mathrm{RC}_{3}, \mathrm{RC}_{6}\right.$ and $\left.\mathrm{RC}_{9}\right)$, the system performance is expressively higher compared to other rack configurations (see Tab. 6). Another important issue is the velocity profile of the elevator (elevators lifting tables), which was in our case moderate $\left(v_{y}=1,5 \mathrm{~m} / \mathrm{s}\right.$ and $a_{y}=1,5 \mathrm{~m} / \mathrm{s}^{2}$ ). In case of efficient drives of the elevators lifting tables, the travel (cycle) time will be lower, which will have a consequence to the system (throughput) performance of the SBS/RS. Of course, the velocity profile for the vertical movement is always limited with physical boundaries of the load that is being hoisted

The proposed method proves to be useful when designing SBS/RS in practice. The proposed method could help the warehouse designer to analyse the efficiency of layout along with the kinematic properties of the SBS/RS in the early stage of project. The potential limitation is that the simulation model of the SBS/RS needs to be developed by warehouse designers, since there is no general simulation model in the market.

For the future work a method for the system (throughput) performance energy consumption and energy regeneration of the SBS/RS should be considered simultaneously. It has been proven that for an efficient SBS/RS design, both throughput performance, energy consumption and energy regeneration aspect should be considered as a single objective function.

\section{References}

[1] Burinskiene A. Optimising Forklift Activities in Wide Aisle Reference Warehouse. // International Journal of Simulation Modelling, 14, 4(2015), pp. 621-632.

[2] DOI:10.2507/IJSIMM14(4)5.312

[3] Van den Berg, J. P.; Zijm, W. H. M. Models for warehouse management: Classification and examples. // International Journal of Production Economics. 59, (1999), pp. 519-528. DOI: 10.1016/S0925-5273(98)00114-5

[4] Malmborg, C. J. Conceptualizing tools for autonomous vehicle storage and retrieval systems. // International Journal of Production Research. 40, 8(2002), pp. 1807 1822. DOI: $10.1080 / 00207540110118668$

[5] Carlo, H. J.; Vis, I. F. A. Sequencing dynamic storage systems with multiple lifts and shuttles. // International Journal of Production Economics. 140, (2012), pp. 844853. DOI: 10.1016/j.jpe.2012.06.035

[6] Lerher, T.; Edl, M.; Rosi, B. Energy efficiency model for the mini-load automated storage and retrieval systems. // International Journal of Advanced Manufacturing Technology. 70, (2013), pp. 97-115. DOI: 10.1007/s00170013-5253-x

[7] Malmborg, C. J. Interleaving rule dynamics in autonomous vehicle storage and retrieval systems. // International Journal of Production Research. 41, 5(2003), pp. 10571069. DOI: $10.1080 / 0020754021000033887$

[8] Kuo, P. H.; Krishnamurthy, A.; Malmborg, C. J. Design models for unit load storage and retrieval systems using autonomous vehicle technology and resource conserving storage and dwell point policies. // Applied Mathematical
Modelling. 31, 10(2007), pp. 2332-2346. DOI: 10.1016/j.apm.2006.09.011

[9] Kuo, P. H.; Krishnamurthy, A.; Malmborg, C. J. Performance modelling of autonomous vehicle storage and retrieval systems using class-based storage policies. // International Journal of Computer Applications in Technology. 31, 4(2008), pp. 238-248. DOI: 10.1504/IJCAT.2008.018160

[10] Fukunari, M.; Malmborg, C. J. An efficient cycle time model for autonomous vehicle storage and retrieval systems. // International Journal of Production Research. 46, 12(2008), pp. 3167-3184. DOl: $10.1080 / 00207540601118454$

[11] Fukunari, M.; Malmborg, C. J. A network queuing approach for evaluation of performance measures in autonomous vehicle storage and retrieval systems. // European Journal of Operational Research. 193, 1(2009), pp. 152-167. DOI: 10.1016/j.ejor.2007.10.049

[12] Zhang, L.; Krishnamurthy, A.; Malmborg, C. J.; Heragu, S. $\mathrm{S}$. Variance-based approximations of transaction waiting times in autonomous vehicle storage and retrieval systems. // European Journal of Industrial Engineering. 3, 2(2009), pp. 146-168. DOI: 10.1504/EJIE.2009.023603

[13] Ekren, B. Y.; Heragu, S. S.; Krishnamurthy, A.; Malmborg, C. J. Simulation based experimental design to identify factors affecting performance of AVS/RS. // Computers \& Industrial Engineering. 58, (2010), pp. 175-185. DOI: 10.1016/j.cie.2009.10.004

[14] Ekren, B. Y. Performance evaluation AVS/RS under various design scenarios: a case study. // International Journal of Advanced Manufacturing Technology. 55, (2011), pp. 1253-1261. DOI: 10.1007/s00170-010-3137-x

[15] Ekren, B. Y.; Heragu, S. S. Simulation based performance analysis of an autonomous vehicle storage and retrieval system. // Simulation Modelling Practice and Theory. 19, (2011), pp. 1640-1650. DOI: 10.1016/j.simpat.2011.02.008

[16] Ekren, B. Y.; Heragu, S. S. Simulation based regression analysis for the rack configuration of autonomous vehicle storage and retrieval system. // International Journal of Production Research. 48, 21(2010), pp. 6257-6274. DOI: 10.1080/00207540903321665

[17] Roy D.; Heragu, S. S.; Krishnamurthy, A.; Malmborg, C. J. Performance analysis and design trade-offs in warehouses with autonomous vehicle technology. // IIE Transactions. 44, 12(2012), pp. 1045-1060. DOI: 10.1080/0740817X.2012.665201

[18] Ekren, B. Y.; Heragu, S. S.; Krishnamurthy, A.; Malmborg, C. J. An approximate solution for semi-open queuing network model of autonomous vehicle storage and retrieval system. // IEEE Transactions on Automation Science and Engineering. $10, \quad(2013), \quad p p . \quad 205-215 . \quad$ DOI: 10.1109/TASE.2012.2200676

[19] Ekren, B. Y.; Heragu, S. S.; Krishnamurthy, A.; Malmborg, C. J. Matrix-geometric solution for semi-open queuing network model of autonomous vehicle storage and retrieval system. // Computers \& Industrial Engineering. 68, (2014), pp. 78-86. DOI: 10.1016/j.cie.2013.12.002

[20] Ekren, B. Y.; Heragu, S. S. Approximate analysis of load dependent general queuing networks with low service time variability. // European Journal of Operational Research. 205, (2010), pp. 381-389. DOI: 10.1016/j.ejor.2010.01.022

[21] Marchet, G.; Melacini, M.; Perotti, S.; Tappia, E. Development of a framework for the design of autonomous vehicle storage and retrieval systems. // International Journal of Production Research. 51, 14(2013), pp. 4365 4387. DOI: $10.1080 / 00207543.2013 .778430$

[22] A multi objective model for optimization of automated warehouses. // Lerher, T.; Borovinšek, M.; Šraml, M. Logistics: perspectives, approaches and challenges. 2013 New York: Nova Publishers, pp. 87-110. 
[23] Modern automation in warehousing by using the shuttle based technology. // Lerher, T. Automation Systems of the 21st Century: New Technologies, Applications and Impacts on the Environment \& Industrial Processes. 2013 New York: Nova Publishers, pp. 51-86.

[24] Lerher, T.; Ekren, B. Y.; Dukic, G.; Rosi, B. Travel time model for shuttle-based storage and retrieval systems. // International Journal of Advanced Manufacturing Technology. 40, (2015), pp. 101-121. DOI: 10.1007/s00170014-6726-2

[25] Smew, W.; Young, P.; Geraghty, J. Supply Chain Analysis Using Simulation, Gaussian Process Modelling and Optimisation. // International Journal of Simulation Modelling. $\quad 12, \quad 3(2013), \quad$ pp. $\quad 178-189$. DOI:10.2507/IJSIMM12(3)4.239

[26] Bekker, J. Multi-objective Buffer Space Allocation with the Cross-entropy Method. // International Journal of Simulation Modelling. 12, 1(2013), pp. 50-61. DOl: 10.2507/IJSIMM12(1)5.228

[27] Ekran, T. E.; Can, G. F. Selecting the best warehouse data collecting system by using AHP and FAHP methods. // Tehnicki vjesnik-Technical Gazette. 21, 1(2014), pp. 87-93.

\section{Authors' addresses}

Associate professor dr. Tone Lerher

University of Maribor, Faculty of Logistics,

Mariborska cesta 7, 3000 Celje, Slovenia

E-mail: tone.lerher@um.si

\section{Associate professor dr. Bojan Rosi}

University of Maribor, Faculty of Logistics,

Mariborska cesta 7, 3000 Celje, Slovenia

E-mail: bojan.rosi@um.si

\section{Assistant professor dr. Banu Yetkin Ekren}

Izmir University of Economics,

Department of Industrial Engineering,

Izmir 35330, Turkey

E-mail: banu.ekren@izmirekonomi.edu.tr

\section{Professor dr. Zaki Sari}

University of Tlemcen,

Manufacturing Engineering Laboratory of Tlemcen,

13000 Tlemcen, Algeria

E-mail: zaki_sari@yahoo.com

\section{Appendix A. Verification of expressions 2 and 4}

Verification of the expression 2 where the peak velocity $v_{p}$ is less than $v_{\max }$.

Condition 1: $0 \leq t \leq t_{p}$

$d_{1}(t)=\int_{0}^{t_{p}} v(t) d t=\int_{0}^{t_{p}} a \cdot t d t=a \cdot \frac{t_{p}^{2}}{2}$

Condition 2: $t_{p} \leq t \leq T$

$d_{2}(t)=\int_{t_{p}}^{T} v(t) d t=\int_{t_{p}}^{T}-a(t-T) d t=\frac{1}{2} a\left(T-t_{p}\right)^{2}$,

Considering the condition $t_{\mathrm{p}}=T / 2$, the distance in dependence on time $d(T)$ equals the next expression:

$d(T)=d_{1}(t)+d_{2}(t)=\frac{a \cdot T^{2}}{4}$,

Verification of the expression 4 where the peak velocity $v_{p}$ is equal to $v_{\max }$.

Condition 1: $0 \leq t \leq t_{p}$

$d_{1}(t)=\int_{0}^{t_{p}} v(t) d t=\int_{0}^{t_{p}} a \cdot t d t=\frac{a t_{p}^{2}}{2}$,

Condition 2: $t_{p} \leq t \leq T-t_{p}$

$d_{2}(t)=\int_{t_{p}}^{T-t_{p}} v(t) d t=\int_{t_{p}}^{T-t_{p}} v_{\max } d t=v_{\max }\left(T-2 t_{p}\right)$

Condition 3: $T-t_{p} \leq t \leq T$

$d_{3}(t)=\int_{T-t_{p}}^{T} v(t) d t=\int_{T-t_{p}}^{T}-a(T-t) d t=\frac{a t_{p}^{2}}{2}$,

Considering the condition $t_{p}=v_{\max } / a$, the distance in dependence on time $d(T)$ equals the next expression:

$d(T)=d_{1}(t)+d_{2}(t)+d_{3}(t)=v_{\max } \cdot T-\frac{v_{\max }^{2}}{a}$, 